\title{
Characterizing Potentially Preventable Hospitalizations of High-Cost Patients in Rural China
}

\section{OPEN ACCESS}

Edited by:

Kingston Rajiah,

Gandhi Institute of Technology and

Management University, India

Reviewed by:

Yudong Miao,

Zhengzhou University, China

Jay Pan,

Sichuan University, China

${ }^{*}$ Correspondence:

Yan Zhang

yanzhang@hust.edu.cn

Specialty section: This article was submitted to

Public Health Policy,

a section of the journal

Frontiers in Public Health

Received: 29 October 2021

Accepted: 17 January 2022

Published: 08 February 2022

Citation:

Lu S, Zhang Y, Zhang L, Klazinga NS and Kringos DS (2022) Characterizing

Potentially Preventable

Hospitalizations of High-Cost Patients in Rural China.

Front. Public Health 10:804734. doi: 10.3389/fpubh.2022.804734

\begin{abstract}
Shan Lu ${ }^{1,2}$, Yan Zhang ${ }^{1,2 *}$, Liang Zhang ${ }^{1,2,3}$, Niek S. Klazinga ${ }^{4}$ and Dionne S. Kringos ${ }^{4}$
${ }^{1}$ School of Medicine and Health Management, Tongji Medical College, Huazhong University of Science and Technology, Wuhan, China, ${ }^{2}$ Research Centre for Rural Health Service, Key Research Institute of Humanities and Social Sciences of Hubei Provincial Department of Education, Wuhan, China, ${ }^{3}$ School of Political Science and Public Administration, Wuhan University, Wuhan, China, ${ }^{4}$ Department of Public and Occupational Health, Amsterdam Public Health Research Institute, University of Amsterdam, Amsterdam University Medical Centers, Amsterdam, Netherlands
\end{abstract}

Introduction: High-cost patients are characterized by repeated hospitalizations, and inpatient cost accounts for a large proportion of their total health care spending. This study aimed to assess the occurrence and costs of potentially preventable hospitalizations and explore contributing factors among high-cost patients in rural China.

Methods: We examined a population-based sample of patients using the 2016 New Rural Cooperative Medical Scheme in Dangyang city, China. Eighteen thousand forty-three high-cost patients were identified. A validated tool and logistic regression analysis were used to determine preventable hospitalizations and their patient-level and supply-side factors.

Results: High-cost patients were older (average age of 54 years) than non-high-cost patients (50 years) and more likely to come from poverty-stricken families. The occurrence of preventable hospitalization was $21.65 \%$ among high-cost patients. The proportion of preventable inpatient cost in total inpatient and outpatient expenditure among high-cost patients (5.81\%) was lower than that of non-high-cost patients (7.88\%) but accounted for $75.87 \%$ of the overall preventable inpatient cost. High-cost patients with more hospitalizations were more likely to experience preventable hospitalization, and those with heart failure, COPD, diabetes and mixed conditions were at a higher risk of preventable hospitalization, while those with more outpatient visits were less likely to show preventable hospitalization.

Conclusions: The occurrence of preventable hospitalization among high-cost patients in rural China was sizeable. The preventable inpatient cost of the overall population was concentrated among high-cost patients. Interventions such as improving preventive care and disease management targeting high-cost patients within counties may improve patients' health outcomes and quality of life and reduce overall preventable inpatient cost.

Keywords: high-cost patients, potentially preventable hospitalization, ambulatory care sensitive conditions, preventable inpatient cost, rural China 


\section{INTRODUCTION}

High-cost patients, the costliest 5 or $10 \%$ of patients who account for more than $50 \%$ of total health spending, are under heated discussion in many high-income countries (1-3). Governments, health insurers and providers are increasingly focusing on high-cost patients and attempting to improve care delivery for them to enhance health outcomes and reduce spending $(1,4)$. However, limited evidence is available on this special population from low-and middle-income countries though a few studies began to pay attention to the cohort recently $(5,6)$. With economies progressing, population aging, rising incomes and medical technological advancements, the total health expenditure has kept rising in recent years in China, which is now an uppermiddle income country (7). From 2011 to 2019, the average annual growth rate of total health expenditure was $14.21 \%$, which is higher than that of gross domestic product (10.28\%) (8). Our previous study showed that the top 5 and $10 \%$ of patients with the highest health spending occupied, respectively, 68 and $81 \%$ of total health spending in rural China (6). Understanding this small proportion of patient cohort better might be critical to improve health outcomes, reduce health care costs and increase efficiency, hence contributing to the financial sustainability of the health system (9).

High-cost patients are characterized by repeated hospitalizations, and related inpatient costs do account for a large proportion of their total health care spending in highincome countries $(10,11)$. The inpatient cost of the costliest $5 \%$ of the patients took up more than $90 \%$ of their total health spending in rural China according to our previous study (6). Therefore, identifying and reducing preventable hospitalizations seems to be the key to decrease the health care spending of high-cost patients. Successful programs targeting high-cost patients with high needs or high risk of unneeded healthcare utilization have demonstrated the possibility of cutting hospital admissions of the high-cost cohort $(12,13)$.

Potentially preventable hospitalizations (PPHs) are defined as conditions that can be managed with timely and effective treatment in the outpatient setting (14), and are identified by ambulatory care sensitive conditions. Ambulatory care sensitive conditions often include chronic conditions, where preventative care should prevent later admission (e.g., complications of diabetes) and conditions for which acute management should prevent admission (e.g., community-acquired pneumonia) (15). The rate of $\mathrm{PPH}$ is often used to evaluate the performance of the primary care system and document possible deficiencies in ambulatory care (16). A large proportion of hospitalizations may be preventable among patients with select chronic diseases $(16,17)$. However, evidence on PPHs among high-cost patients remains limited. To our knowledge, only few studies on $\mathrm{PPH}$ from the US have focused on high-cost patients; the preventable

\footnotetext{
Abbreviations: PPH, potentially preventable hospitalizations; NCMS, New Rural Cooperative Medical Scheme; CHS-DRG, China Healthcare Security Diagnosis Related Groups; ICD-10, the 10th revision of the International Classification of Diseases; ADRG, adjacent diagnosis-related groups; MDC, major diagnostic categories; COPD, chronic obstructive pulmonary disease.
}

spending of these patients was estimated at a maximum of $13.3 \%$ of spending, and that of high-cost Medicare patients accounted for more than $70 \%$ of the total preventable spending among all Medicare patients $(9,18-20)$.

In China, citizens are free to choose their first-contact health care facility; they generally have little trust in primary care and usually bypass primary care facilities to seek health care in hospitals (21). We suspect that patients (including high-cost patients) in China may spend more on PPHs than in many highincome countries due to their distrust of primary care and their tendency to bypass primary care facilities. Zhang et al. revealed that the inappropriate hospital admission rate in five counties of China reached $27.6 \%$ in 2014 (22). Chen and Pan reported that $31.1 \%$ of rural elderly patients had PPHs from 2014 to 2017 (23). However, the frequency and occurrence of PPH, the degree to which PPH spending accounts for the total spending among high-cost patients and the difference between high-cost and non-high-cost patients are largely unknown. To determine ways to reduce PPHs, we need to understand factors that drive these hospitalizations. To date, patient-level and supplyside factors are known to be associated with PPHs. Patientlevel factors range from demographic, socioeconomic and health characteristics to health behavior and medication adherence (2426). Supply-side factors include supply of and access to primary healthcare services, clinician adherence to clinical guidelines for disease management and physicians' experience and preference regarding admission $(25,27,28)$. However, limited information is known about the contributing factors of PPHs for highcost patients.

Our earlier study focusing on high-cost patients in rural China showed that the average out-of-pocket spending exceeded $30 \%$ of the consumption expenditure per capita (29). The accessibility and quality of care in rural areas are worse than those in cities, and families living in rural areas are more likely to suffer from catastrophic health expenditure (30). The present study focuses on high-cost patients in rural area to assess the occurrence and costs of PPHs and explore the contributing factors among high-cost patients in rural China. We address the following research questions:

1. What are the demographic, socioeconomic, healthcare utilization and clinical characteristics of high-cost patients compared with non-high-cost patients?

2. What is the occurrence of PPHs among high-cost and nonhigh-cost patients?

3. What are the associated costs of PPHs among high-cost and non-high-cost patients?

4. What patient and supply-side factors are associated with PPHs among high-cost patients in rural China?

\section{MATERIALS AND METHODS Study Setting}

This population-based retrospective study was performed in Dangyang city, Hubei province. Dangyang, a county-level rural area in Central China, has 331,349 rural residents and a gross regional product per capita of US\$14,628.2 in 2016 
(Exchange rate in 2016: RMB $¥ 6.64$ to US\$1.00), which is higher than the gross domestic product per capita of China (US\$8147.9). All rural residents were covered by the New Rural Cooperative Medical Scheme (NCMS), which offered reimbursement for outpatient and inpatient services in health care facilities at different levels. Dangyang has 145 village clinics, 10 township health centers and 3 county hospitals (including a general hospital, a maternal and child health hospital and a traditional Chinese medicine hospital). Village clinics and township health centers provide primary care. Township health centers and county hospitals provide inpatient services in rural China. The health care utilization and health expenditure of every resident covered by the NCMS were recorded in the NCMS database.

\section{Procedures}

We collected data from the 2016 NCMS database of Dangyang. Patients in the highest $10 \%$ of total individual spending (including inpatient and outpatient spending) were defined as high-cost patients. The top $10 \%$ of patients were identified in accordance with previous studies on preventable spending of high-cost patients $(9,18,19)$. A total of 180,431 patients who utilized inpatient or outpatient services in 2016 were included in this study, among which 18,043 were highcost patients. Demographic characteristics included age and gender. Family income (i.e., total family income) was used to describe the socioeconomic status of patients. Patients were classified into poverty-stricken family or non-povertystricken family according to the Poverty Alleviation Information System. Health care utilization of patients was represented by hospitalization frequency, average length of stay and admission pattern in 2016. Admission pattern referred to the types of health care facility where the patient was hospitalized. Clinical characteristics of patients were analyzed using all of the principle diagnosis of hospitalizations and outpatient visits in 2016. The principle diagnosis of hospitalizations and outpatient visits were categorized according to the China Healthcare Security Diagnosis Related Groups (CHS-DRG) for each patient (31). Based on the similarity of clinical process and resource consumption, CHS-DRG categorizes the 10th revision of the International Classification of Diseases (ICD10) codes into 187 adjacent diagnosis-related groups (ADRG), such as chronic obstructive airway disease and hypertension. Each ADRG can be classified as one of the major diagnostic categories (MDC), such as respiratory diseases and circulatory system diseases. The lists of MDC and ADRG are presented in Supplementary File 1. To show additional information, we adopted ADRGs instead of MDCs in describing the clinical characteristics of patients. Neoplasms were frequently reported among high-cost patients (10), while CHS-DRG splits neoplasms into different MDCs; to capture the clinical characteristics of high-cost patients, we merged ADRGs that were related to neoplasms (e.g., respiratory system tumor, digestive system malignant tumor) in different MDCs into one group, that is, neoplasms. The ADRGs included in group neoplasms are described in Supplementary File 1.

\section{Measures}

\section{Potentially Preventable Hospitalization}

The ICD-10 codes for principle diagnosis of hospitalizations were extracted from the NCMS database. PPHs were identified according to the Agency for Healthcare Research and Quality Prevention Quality Indicators algorithm, which defines PPHs as those related to conditions, such as heart failure, diabetes, hypertension and asthma, for which good outpatient care can likely prevent the need for hospitalization (32). The tool was validated and used in a prior work on rural populations in China (23). The list of ICD-10 codes used to identify PPHs is shown in Supplementary File 2.

\section{Associated Factors of Potentially Preventable Hospitalization}

We adopted Anderson's Behavioral Model of Health Services Use (BMHSU) (33) as a theoretical framework to analyze potential factors associated with PPHs. According to BMHSU, health services use was determined by (1) existing characteristics that predispose people to use or not use services even though these characteristics are not directly responsible for use (e.g., age, gender), (2) enabling characteristics that facilitate or impede use of services (e.g., income, insurance, health system factors) and (3) need or conditions that laypeople or health care providers recognize as requiring medical treatment (33). The patient-level and supply-side factors included in this study can be divided into four categories, namely, predisposing characteristics (including age and gender), enabling characteristics (including family income, supply of primary care physicians, availability of medicines, primary care beds capacity and time to county hospital), need characteristics (i.e., ambulatory care sensitive conditions) and health care utilization characteristics (including hospitalization frequency, outpatient visits and admission pattern). We included health care utilization characteristics to reflect the utilization habit of the patient. The definitions and categories of the associated factors are shown in Supplementary File 3. Supply-side factors, except for time to county hospital, were collected from the 2016 Health Statistical Annual Report. Time to county hospital was individually captured using Google Maps. High cost patients with more than one ambulatory care sensitive conditions were classified into one group labeled "mixed conditions", which accounted for $16.69 \%$ of all high-cost patients with ambulatory care sensitive conditions.

\section{Statistical Analysis}

Given that the patients were from 10 different towns with various primary care resources, we tested the existence of sufficient variance at the cluster level in influencing $\mathrm{PPH}$ by multilevel logistic regression analysis. High-cost patients with ambulatory care sensitive conditions were included to identify the associated factors of PPHs for high-cost patients. The dependent variable was a binary variable with a value of 1 indicating one or more PPHs were experienced. The null model (i.e., interceptonly model) was first generated and the interclass correlation coefficient was then computed. Result showed the interclass correlation coefficient was 0.0096 , indicating that incorporating a 
multilevel perspective would not be more effective in confirming the associated factors of PPHs than focusing only at the individual level. Therefore, logistic regression analysis was finally conducted to identify the associated factors of PPHs for high-cost patients. Differences in predicting PPH among categories were compared by odd ratios. Goodness-of-fit of the model was examined by Hosmer-Lemeshow goodness-of-fit test,-2log likelihood and percent correctly classified. Statistical significance was set to two-tailed $p<0.05$. All analyses were conducted in Stata 15.1.

\section{Ethics Approval and Consent to Participate}

This study was approved by the Ethics Committee of Tongji Medical College, Huazhong University of Science and Technology (IORG No: IORG0003571).

\section{RESULTS}

\section{Study Sample}

Table 1 presents the description of the overall, high-cost and non-high-cost patients. The average age of high-cost patients (53.57 years) was higher than that of overall (48.53 years) and non-high-cost (47.97 years) patients. The proportion of patients from poverty-stricken families in the high-cost group $(7.85 \%)$ was more than twice of that in overall patients (3.73\%). On average, high-cost patients had 2 hospitalizations a year. The average length of stay of high-cost patients was 11.77 days, which was higher than those of the overall (9.37 days) and non-high-cost (7.21 days) patients. Approximately half of highcost patients (55.72\%) had only one admission, and $21 \%$ of high-cost patients had three or more than three admissions a year. More than half of high-cost patients (54.66\%) were only hospitalized in county hospitals. Among their top 10 ADRGs, high-cost patients had higher burden of coronary atherosclerosis/thrombus/occlusion, cerebral ischemic disease, hypertension, chronic obstructive airway disease and neoplasms than overall or non-high-cost patients.

\section{Potentially Preventable Hospitalizations and Preventable Inpatient Costs}

Table 2 shows PPHs and preventable inpatient costs among overall, high-cost and non-high-cost patients. The occurrence of $\mathrm{PPH}$ among high-cost group was $21.65 \%$, which was higher than that among overall patients (3.82\%) and non-high-cost patients (1.83\%). The proportion of PPHs in total admissions in the highcost group (11.03\%) was slightly lower than that in the nonhigh-cost group (13.44\%). Among high-cost patients, $92.63 \%$ of PPHs occurred within the county, and PPHs at township health centers and county hospitals accounted for 50.30 and $42.33 \%$ of total PPHs, respectively. The proportion of PPHs in total admissions at township health centers among highcost patients was $22.60 \%$, which was almost three times of that at county hospitals. Preventable inpatient cost of high-cost patients was US $\$ 2,167,898.26$, which amounted to $75.87 \%$ of the total preventable spending of overall patients. Township health centers and county hospitals accounted for 23.24 and $58.68 \%$ of preventable spending among high-cost patients, respectively.
TABLE 1 | Characteristics of overall, high-cost and non-high-cost patients.

\begin{tabular}{|c|c|c|c|}
\hline & $\begin{array}{c}\text { Overall } \\
(n=18,0431)\end{array}$ & $\begin{array}{c}\text { High-cost } \\
\text { patients } \\
(n=18,043)\end{array}$ & $\begin{array}{l}\text { Non-high- } \\
\text { cost patients } \\
(n=162,388)\end{array}$ \\
\hline Age (mean, SD) & $48.53(20.24)$ & $53.57(20.70)$ & $47.97(20.11)$ \\
\hline \multicolumn{4}{|l|}{ Gender (n, \%) } \\
\hline Female & $95,166(52.74)$ & 9,933 (55.05) & $85,233(52.49)$ \\
\hline Male & $85,265(47.26)$ & $8,110(44.95)$ & $77,155(47.51)$ \\
\hline \multicolumn{4}{|l|}{ Family income $(n, \%)$} \\
\hline Poverty-stricken & 6,723 (3.73) & $1,417(7.85)$ & $5,306(3.27)$ \\
\hline Non-poverty-stricken & $\begin{array}{c}173,708 \\
(96.27)\end{array}$ & $16,626(92.15)$ & $\begin{array}{c}157,082 \\
(96.73)\end{array}$ \\
\hline Admissions (mean, SD) & $0.32(0.88)$ & $1.97(1.84)$ & $0.14(0.38)$ \\
\hline \multicolumn{4}{|l|}{ Admissions ( $n, \%)$} \\
\hline 0 & $\begin{array}{c}142,178 \\
(78.80)\end{array}$ & $10(0.06)$ & $\begin{array}{c}142,168 \\
(87.55)\end{array}$ \\
\hline 1 & $28,412(15.75)$ & $10,053(55.72)$ & $18,359(11.31)$ \\
\hline 2 & $5,957(3.30)$ & $4,187(23.21)$ & $1,770(1.09)$ \\
\hline 3 & $1,986(1.10)$ & 1,899 (10.52) & $87(0.05)$ \\
\hline$>3$ & $1,898(1.05)$ & 1,894 (10.50) & $4(0.002)$ \\
\hline Average LOS (mean, SD) & $9.37(8.30)$ & $11.77(10.60)$ & $7.21(4.47)$ \\
\hline \multicolumn{4}{|l|}{ Admission pattern (n, \%) } \\
\hline Only township health center & 10,674 (5.92) & $1,018(5.64)$ & 9,656 (5.95) \\
\hline Only county hospital & $18,786(10.41)$ & $9,862(54.66)$ & $8,924(5.50)$ \\
\hline Only outside of the county & $3,609(2.00)$ & 2,372 (13.15) & $1,237(0.76)$ \\
\hline Mixed facilities & $5,184(2.87)$ & $4,781(26.50)$ & $403(0.25)$ \\
\hline No admissions & $\begin{array}{c}142,178 \\
(78.80)\end{array}$ & $10(0.06)$ & $\begin{array}{c}142,168 \\
(87.55)\end{array}$ \\
\hline \multicolumn{4}{|l|}{$\begin{array}{l}\text { Top } 10 \text { ADRGs of high-cost } \\
\text { patients }^{a}\end{array}$} \\
\hline $\begin{array}{l}\text { Upper respiratory tract } \\
\text { infection and tympanitis }\end{array}$ & $81,226(45.02)$ & $5,363(29.72)$ & $75,863(46.72)$ \\
\hline Neck and back disease & $26,626(14.76)$ & $2,680(14.85)$ & $23,946(14.75)$ \\
\hline $\begin{array}{l}\text { Gastroenteritis and } \\
\text { esophagitis }\end{array}$ & $24,241(13.44)$ & $2,403(13.32)$ & $21,838(13.45)$ \\
\hline $\begin{array}{l}\text { Coronary atherosclerosis/ } \\
\text { thrombus/ occlusion }{ }^{\text {b }}\end{array}$ & $7,560(4.19)$ & $2,077(11.51)$ & $5,483(3.38)$ \\
\hline $\begin{array}{l}\text { Cerebral ischaemic } \\
\text { disease }^{c}\end{array}$ & $4,223(2.34)$ & 2,002 (11.10) & $2,221(1.37)$ \\
\hline Hypertension & $14,724(8.16)$ & $1,824(10.11)$ & $12,900(7.94)$ \\
\hline $\begin{array}{l}\text { Other digestive system } \\
\text { disease }^{d}\end{array}$ & 7,694 (4.26) & $1,649(9.14)$ & $6,045(3.72)$ \\
\hline $\begin{array}{l}\text { Chronic obstructive airway } \\
\text { disease }^{e}\end{array}$ & 6,100 (3.38) & $1,523(8.44)$ & $4,577(2.82)$ \\
\hline $\begin{array}{l}\text { Acute bronchitis and } \\
\text { pertussis }\end{array}$ & $17,806(9.87)$ & $1,449(8.03)$ & $16,357(10.07)$ \\
\hline Neoplasms & $1,433(0.79)$ & $1,229(6.81)$ & $204(0.126)$ \\
\hline
\end{tabular}

${ }^{a}$ The ADRGs listed are the top 10 adjacent diagnosis related groups with the highest prevalence among high-cost patients. The prevalence of all adjacent diagnosis-related groups among high-cost, non-high-cost and overall patients are shown in reverse order in Supplementary File 4.

${ }^{b}$ Coronary atherosclerosis/thrombus/occlusion was represented by coronary atherosclerotic heart disease.

${ }^{c}$ Cerebral ischaemic disease was represented by cerebral infarction.

${ }^{d}$ Other digestive system disease was represented by diseases requiring surgical operation (e.g., hemorrhoids, acute appendicitis, polyp, anal fissure).

${ }^{e}$ Chronic obstructive airway disease was represented by chronic obstructive pulmonary disease (COPD). 
TABLE 2 | Occurrence and costs of potentially preventable hospitalizations among high-cost and non-high-cost patients.

\begin{tabular}{|c|c|c|c|}
\hline & $\begin{array}{c}\text { Overall } \\
(n=180,431)\end{array}$ & $\begin{array}{l}\text { High-cost } \\
\text { patients } \\
(n=18,043)\end{array}$ & $\begin{array}{l}\text { Non-high- } \\
\text { cost patients } \\
(n=162,388)\end{array}$ \\
\hline \multicolumn{4}{|c|}{ Potentially preventable hospitalizations } \\
\hline Total number (n, \%) & $6,886(100)$ & $3,907(56.74)$ & $2,979(43.26)$ \\
\hline $\begin{array}{l}\text { Admission facility type ( } n, \%) \\
\text { Township health centers }\end{array}$ & $3,965(57.58)$ & $1,965(50.30)$ & $2,000(67.14)$ \\
\hline County hospitals & $2,566(37.26)$ & $1,654(42.33)$ & $912(30.61)$ \\
\hline Outside of the county & $355(5.16)$ & $288(7.37)$ & $67(2.25)$ \\
\hline Occurrence of $\mathrm{PPH}(\%)^{\mathrm{a}}$ & 3.82 & 21.65 & 1.83 \\
\hline $\begin{array}{l}\text { Proportion of PPHs in total } \\
\text { admissions }(\%)^{b}\end{array}$ & 11.96 & 11.03 & 13.44 \\
\hline At township health centers ${ }^{c}$ & 20.00 & 22.60 & 17.97 \\
\hline At county hospitals & 8.39 & 7.93 & 9.36 \\
\hline $\begin{array}{l}\text { At hospitals outside of the } \\
\text { county }\end{array}$ & 4.96 & 4.92 & 5.18 \\
\hline \multicolumn{4}{|l|}{ Preventable inpatient costs } \\
\hline Total spending (\$, \%) & $\begin{array}{c}2,857,558.45 \\
(100)\end{array}$ & $\begin{array}{c}2,167,898.26 \\
(75.87)\end{array}$ & $\begin{array}{c}689,660.19 \\
(24.13)\end{array}$ \\
\hline $\begin{array}{c}\text { Admission facility type }(\$, \%) \\
\text { Township health centers }\end{array}$ & $\begin{array}{l}892,263.56 \\
(31.22)\end{array}$ & $\begin{array}{c}503,868.95 \\
(23.24)\end{array}$ & $\begin{array}{c}388,394.61 \\
(56.32)\end{array}$ \\
\hline County hospitals & $\begin{array}{c}1,548,929.43 \\
(54.2)\end{array}$ & $\begin{array}{c}1,272,186.28 \\
(58.68)\end{array}$ & $\begin{array}{c}276,743.14 \\
(40.13)\end{array}$ \\
\hline Outside of the county & $\begin{array}{c}416,365.47 \\
(14.57)\end{array}$ & $\begin{array}{l}391,843.03 \\
(18.07)\end{array}$ & $\begin{array}{c}24,522.43 \\
(3.56)\end{array}$ \\
\hline Preventable spending per PPH (\$) & 414.98 & 554.88 & 231.51 \\
\hline $\begin{array}{l}\text { Proportion of preventable } \\
\text { spending in total expenditure (\%) }\end{array}$ & 6.20 & 5.81 & 7.88 \\
\hline
\end{tabular}

${ }^{a}$ Occurrence of $\mathrm{PPH}=$ number of $\mathrm{PPH} /$ number of patients.

${ }^{b}$ Proportion of PPHs in total admissions (\%) = number of PPHs/number of admissions.

${ }^{c}$ Proportion of PPHs in total admissions at township health centers (\%) = number of PPHs

at township health centers/number of admissions at township health centers.

The proportion of preventable spending in medical expenditure (including inpatient and outpatient expenditure) among highcost patients was $5.81 \%$, which was lower than that $(7.88 \%)$ among non-high-cost patients.

\section{Factors Associated With Potentially Preventable Hospitalizations}

In total, there were 4,331 high-cost patients with ambulatory care sensitive conditions and $57.52 \%$ of them experienced one or more PPHs in 2016. Factors associated with PPHs among highcost patients were examined using a logistic regression model (Table 3). Patients with older age $(\mathrm{OR}=0.99, p<0.01)$ and more outpatient visits $(\mathrm{OR}=0.94, p<0.01)$ were at a lower risk of experiencing PPHs, while those with more hospitalizations (OR $=1.21, p<0.01$ ) were more likely to experience PPHs. None of supply-side factors was significantly associated with PPHs. Compared with patients who were only hospitalized at township health centers, those with other admission patterns (including only hospitalized at county hospitals, only hospitalized outside the county and mixed admissions) were less likely to experience PPHs. Compared with patients with asthma, those with COPD
TABLE 3 | Factors associated with potentially preventable hospitalizations among high-cost patients.

\begin{tabular}{|c|c|c|c|c|}
\hline \multirow[t]{2}{*}{ Covariates } & \multirow[t]{2}{*}{ OR } & \multirow[t]{2}{*}{$P$-values } & \multicolumn{2}{|c|}{$95 \% \mathrm{Cl}$ for OR } \\
\hline & & & Lower & Upper \\
\hline \multicolumn{5}{|l|}{ Gender (ref: female) } \\
\hline Male & 1.01 & 0.92 & 0.87 & 1.17 \\
\hline Age & 0.99 & $<0.01$ & 0.98 & 0.99 \\
\hline \multicolumn{5}{|l|}{$\begin{array}{l}\text { Family income (ref: } \\
\text { non-poverty-stricken) }\end{array}$} \\
\hline Poverty-stricken & 1.02 & 0.85 & 0.81 & 1.30 \\
\hline Supply of primary care physicians & 1.07 & 0.06 & 1.00 & 1.15 \\
\hline Primary care beds capacity & 0.98 & 0.06 & 0.96 & 1.00 \\
\hline Availability of medicines & 1.00 & 0.17 & 1.00 & 1.00 \\
\hline Time to county hospital & 1.00 & 0.45 & 0.99 & 1.00 \\
\hline Hospitalization frequency & 1.21 & $<0.01$ & 1.14 & 1.28 \\
\hline Outpatient visits & 0.94 & $<0.01$ & 0.94 & 0.95 \\
\hline \multicolumn{5}{|l|}{$\begin{array}{l}\text { Admission pattern (ref: Only } \\
\text { township health center) }\end{array}$} \\
\hline Only county hospital & 0.34 & $<0.01$ & 0.26 & 0.44 \\
\hline Only outside of the county & 0.27 & $<0.01$ & 0.19 & 0.40 \\
\hline Mixed & 0.77 & 0.04 & 0.60 & 0.98 \\
\hline \multicolumn{5}{|l|}{$\begin{array}{l}\text { Ambulatory care sensitive } \\
\text { condition (ref: Asthma) }\end{array}$} \\
\hline COPD & 2.81 & $<0.01$ & 1.89 & 4.17 \\
\hline Diabetes & 1.87 & $<0.01$ & 1.22 & 2.85 \\
\hline Heart failure & 11.23 & $<0.01$ & 3.97 & 31.74 \\
\hline Hypertension & 0.34 & $<0.01$ & 0.23 & 0.50 \\
\hline $\begin{array}{l}\text { Community-acquired } \\
\text { pneumonia }\end{array}$ & 0.97 & 0.90 & 0.62 & 1.53 \\
\hline Urinary tract infection & 0.73 & 0.17 & 0.46 & 1.14 \\
\hline Mixed conditions & 3.15 & $<0.01$ & 2.09 & 4.75 \\
\hline Constant & 5.33 & $<0.01$ & 2.75 & 10.33 \\
\hline -2Log likelihood & \multicolumn{4}{|c|}{$4,492.13$} \\
\hline $\begin{array}{l}\text { Hosmer-Lemeshow } \\
\text { goodness-of-fit test }\end{array}$ & \multicolumn{4}{|c|}{$P=0.39$} \\
\hline Percent correctly classified & \multicolumn{4}{|c|}{$74.57 \%$} \\
\hline
\end{tabular}

$(\mathrm{OR}=2.81, p<0.01)$, diabetes $(\mathrm{OR}=1.87, p<0.01)$, heart failure $(\mathrm{OR}=11.23, p<0.01)$ and mixed conditions $(\mathrm{OR}=$ $3.15, p<0.01)$ were at a higher risk of experiencing PPHs, while those with hypertension $(\mathrm{OR}=0.34, p<0.01)$ were less likely to experience PPHs.

\section{DISCUSSION}

This study aimed to assess the occurrence and costs of PPHs and explore the contributing factors among high-cost patients in rural China. High-cost patients were older (average age of 54 years) than non-high-cost patients (50 years old) and more likely to come from poverty-stricken families. High-cost patients utilized more inpatient services and were hospitalized twice a year on average. For the top 10 ADRGs of highcost patients, coronary atherosclerosis, cerebral ischemic disease, hypertension, chronic obstructive airway disease and neoplasms 
were more prevalent among high-cost patients. The occurrence of PPH was $21.65 \%$, which was higher than that of non-highcost patients (1.83\%). The proportion of preventable inpatient cost in total inpatient and outpatient expenditure among highcost patients $(5.81 \%)$ was lower than that of non-high-cost patients $(7.88 \%)$. However, the preventable inpatient cost of high-cost patients amounted to $75.87 \%$ of the total preventable inpatient cost of overall patients. Age, hospitalization frequency, outpatient visits, admission pattern and ambulatory care sensitive conditions were associated with PPH. Supply side factors (i.e., access and availability of services) were not related to PPH.

The occurrence of PPH among high-cost patients was sizable (21.65\%), indicating that $22 \mathrm{PPHs}$ occurred per 100 high-cost persons. The occurrence of PPHs among high-cost patients was higher than that among non-high-cost patients (1.83\%) and even higher than among patients older than 60 years (17.9\%) as reported by Chen and Pan (23). However, the proportion of PPHs in total admissions among high-cost group (11.03\%) was slightly lower than that among non-high-cost group (13.44\%). The opposite results of the two indicators (i.e., the occurrence and the proportion) may be due to the difference in hospitalization rates (measured as the number of admissions divided by the number of patients) between nonhigh-cost group (14\%) and high-cost group (197\%). According to the occurrence of $\mathrm{PPH}$, it is much more common for highcost patients to experience PPH. Reducing PPH may therefore be conducive to improving patients' health outcomes and quality of life. Health promoting strategies to realize this, such as preventive care and disease management, need to be further studied. The preventable inpatient cost of high-cost patients accounted for the majority $(75.87 \%)$ of total preventable spending of overall patients, consistent with previous findings $(9,19,20)$. Hence, high-cost patients could be the key focus of policy makers or health insurers who aim to reduce preventable inpatient costs. The proportion of preventable spending in the health care expenditure of high-cost patients (5.81\%) were not high in this study, which may imply that the ability to cut down the total cost of this cohort by lowering preventable hospitalizations seems to be limited. However, this result may be due to the measurement of PPHs which were said to be narrow and could have included other diagnostic categories $(10,20)$, and because variations among patients were not addressed. High-cost patients were a highly heterogeneous cohort, which has substantial variations in demographics, functional status and disease burden $(34,35)$. Figueroa and colleagues studied a Medicare population and showed that potentially preventable spending was concentrated in high-cost, frail elderly persons (19). Therefore, preventable spending could vary considerably among different subgroups of high-cost patients in rural China, which needs to be further addressed. Although the proportion of preventable spending among high-cost patients may be small according to this study and prior work, the downstream spending generated by the initial event was not considered (19).

The distribution of PPHs and preventable inpatient costs among different facility types was analyzed. We can conclude that most of PPHs (more than 90\%) and costs (more than 80\%) occurred within the county, which makes it easier to manage
PPHs because the lowest healthcare administrative departments are at county level and most health resources are invested and allocated within counties. PPHs at township health centers accounted for half $(50.3 \%)$ of the total PPHs, and preventable inpatient cost at county hospitals occupied $58.68 \%$ of the total preventable spending among high-cost patients. Hence, both types of facility should be the focus to reduce preventable spending. Township health centers, as primary care facilities that provide inpatient services, presented higher probability of $\mathrm{PPH}$ (22.6\%) than county hospitals $(7.93 \%)$. The result may be due to clinical uncertainty given the relatively lower staff capacity (36) or could be physician-induced demand as a result of a lower bed occupancy rate and economic incentives at primary care facilities $(22,37)$. Patients usually bypass primary care facilities to seek health care in hospitals in China (21); therefore, lack of primary care services might be a key reason for PPHs at county hospitals.

The logistic regression results showed that high-cost patients with older age were less likely to experience PPHs, which was inconsistent with previous studies on the PPHs of the general population $(16,24)$. This may be because high-cost patients with older age are often with comorbidities and hospitalized with more severe and complex diseases rather than ambulatory care sensitive conditions $(4,10)$. High-cost patients with more hospitalizations were at a higher risk of PPHs, indicating that high-cost patients with repeated hospitalizations can be a priority of policies. Moreover, high-cost patients with more outpatient visits were at a lower risk of $\mathrm{PPHs}$, which demonstrate that utilization of outpatient care may help reducing PPHs if better preventive care or disease management was provided at an earlier stage in outpatient settings. All of the supply-side factors, including supply of primary care physicians, primary care bed capacity and availability of medicines, were not significantly associated with PPHs. The results were not in accordance with several studies on the relationship between accessibility of primary care and PPHs $(14,28)$, which may be due to the fact that primary care facilities (i.e., township health centers) provide inpatient services in China or that we only included 10 towns in this study so it is difficult to find differences among such a small number of samples. In many countries, the rates of PPH are often used as an indicator to assess the accessibility and quality of primary care $(16,25,26)$; however, the present study implies careful consideration of application of the indicator in China. Patients with COPD, diabetes and heart failure were more likely to experience PPH compared with those with asthma, which may result from the fact that COPD, diabetes and heart failure were not well-managed at primary care level (38-40), indicating that prevention and treatment of these disease need to be improved in rural China. Patients with hypertension were less likely to experience $\mathrm{PPH}$, which may be due to the fact that hypertension management is provided freely to residents as a public health service by primary care providers since 2009 . Interestingly, patients with heart failure, a large proportion of which resulted from hypertension (40), were at a notably higher risk of experiencing PPH (shown by the largest odd ratio). This indicated that hypertension management provided by primary care needs to be improved to delay progression of the disease. 
This study broadens our understanding of preventable hospitalizations among high-cost patients from non-highincome countries. We focused not only on the cost but also the occurrence of preventable hospitalizations among high-cost cohort to show that it is not just a financial sustainability issue but more a quality of care and health outcome improvement issue. This study has limitations. With only principle diagnosis available to define PPHs, we did not exclude patients with severe complications or comorbidities. Given that previous study from rural China showed that the proportion of exclusion admissions in PPHs was smaller than $0.8 \%$, we believe that the overestimation of the number of PPHs was slight in the present work.

\section{CONCLUSIONS}

In conclusion, among rural patients in the top decile of inpatient and outpatient spending in 2016, the occurrence of $\mathrm{PPH}$ was sizable. The high number of $\mathrm{PPH}$ should be reduced by interventions within counties to improve the health outcomes and quality of life of high-cost patients. Interventions aiming at improving preventive care and disease management may be helpful but still need to be further studied. Overall preventable inpatient cost was concentrated among high-cost patients, indicating that the cohort could be the focus of policy makers and health insurers who want to reduce preventable inpatient cost. However, the ability to cut down the total cost of high-cost patients through lowering preventable hospitalizations seems to be limited. Primary care facilities (i.e., township health centers) and county hospitals need to be the foci for reducing preventable hospitalizations and spending. Further research is required to understand which subgroups of high-cost patients have disproportional preventable spending and identify clinician-, organizational- and system-level factors associated with preventable hospitalizations at primary care facilities and county hospitals. Moreover, secondary diagnosis needs to be well-recorded at health care facilities and health insurance systems to provide a clearer picture of the morbidity patterns of high-cost patients in rural China.

\section{REFERENCES}

1. Blumenthal D, Chernof B, Fulmer T, Lumpkin J, Selberg J. Caring for highneed, high-cost patients - an urgent priority. N Engl J Med. (2016) 375:909-11. doi: 10.1056/NEJMp1608511

2. Wammes JJG, Tanke M, Jonkers W, Westert GP, Wees PV der, Jeurissen PP. Characteristics and healthcare utilisation patterns of high-cost beneficiaries in the Netherlands: a cross-sectional claims database study. BMJ Open. (2017) 7:e017775. doi: 10.1136/bmjopen-2017-017775

3. Hartmann J, Jacobs S, Eberhard S, von Lengerke T, Amelung V. Analysing predictors for future high-cost patients using German SHI data to identify starting points for prevention. Eur J Public Health. (2016) 26:549-55. doi: 10.1093/eurpub/ckv248

4. Hayes SL, Salzberg CA, McCarthy D, Abrams MK, Shah T, Anderson GF. High-need, high-cost patients: who are they and how do they use health care? Issue Brief Commonw Fund. (2016) 26:1-14.

5. Miao Y, Qian D, Sandeep S, Ye T, Niu Y, Hu D, et al. Exploring the characteristics of the high-cost population from the family perspective: a

\section{DATA AVAILABILITY STATEMENT}

The datasets used and analyzed during the current study are available from the corresponding author on reasonable request.

\section{ETHICS STATEMENT}

The studies involving human participants were reviewed and approved by the Ethics Committee of Tongji Medical College, Huazhong University of Science and Technology. Written informed consent from the participants' legal guardian/next of kin was not required to participate in this study in accordance with the national legislation and the institutional requirements.

\section{AUTHOR CONTRIBUTIONS}

SL, YZ, LZ, NK, and DK designed the study. SL and LZ acquired the data. SL and $\mathrm{YZ}$ conducted the data cleaning and statistical analysis. SL drafted the manuscript, which all authors substantially reviewed and revised. All authors read and approved the final manuscript.

\section{FUNDING}

This research was funded by the National Natural Science Foundation of China (Grant nos: 71734003 and 72104086). The organization had no role in the study design, data collection, analysis and interpretation and in writing the manuscript.

\section{ACKNOWLEDGMENTS}

We thank our colleagues for their effort in the data collection and the local site for its participation in the investigation.

\section{SUPPLEMENTARY MATERIAL}

The Supplementary Material for this article can be found online at: https://www.frontiersin.org/articles/10.3389/fpubh. 2022.804734/full\#supplementary-material

cross-sectional study in Jiangsu Province, China. BMJ Open. (2017) 7:e017185. doi: 10.1136/bmjopen-2017-017185

6. Zhang Y, Lu S, Niu Y, Zhang L. Medical expenditure clustering and determinants of the annual medical expenditures of residents: a populationbased retrospective study from rural China. BMJ Open. (2018) 8:e022721. doi: 10.1136/bmjopen-2018-022721

7. World Bank. New Country Classifications by Income Level (2017-2018). Available online at: https://blogs.worldbank.org/opendata/new-countryclassifications-income-level-2017-2018 (accessed May 20, 2021).

8. National Health Commission of the People's Republic of China. China Health Statistical Yearbook 2020. Beijing: Peking Union Medical College Publishing House (2020).

9. Joynt KE, Gawande AA, Orav EJ, Jha AK. Contribution of preventable acute care spending to total spending for high-cost medicare patients. JAMA. (2013) 309:2572-8. doi: 10.1001/jama.2013.7103

10. Wammes JJG, van der Wees PJ, Tanke MAC, Westert GP, Jeurissen PPT. Systematic review of high-cost patients' characteristics and healthcare utilisation. BMJ Open. (2018) 8:e023113. doi: 10.1136/bmjopen-2018-023113 
11. Zook CJ, Moore FD. High-cost users of medical care. N Engl J Med. (1980) 302:996-1002. doi: 10.1056/NEJM198005013021804

12. Delaney RK, Sisco-Taylor B, Fagerlin A, Weir P, Ozanne EM. A systematic review of intensive outpatient care programs for high-need, high-cost patients. Transl Behav Med. (2020) 10:1187-99. doi: 10.1093/tbm/ibaa017

13. Hong CS, Siegel AL, Ferris TG. Caring for high-need, high-cost patients: what makes for a successful care management program? Issue Brief Commonw Fund. (2014) 19:1-19. doi: 10.15868/socialsector.25007

14. Bindman $\mathrm{AB}$, Grumbach K, Osmond D, Komaromy M, Vranizan K, Lurie N, et al. Preventable hospitalizations and access to health care. JAMA. (1995) 274:305-11. doi: 10.1001/jama.1995.03530040033037

15. Purdy S, Griffin T, Salisbury C, Sharp D. Ambulatory care sensitive conditions: terminology and disease coding need to be more specific to aid policy makers and clinicians. Public Health. (2009) 123:169-73. doi: 10.1016/j.puhe.2008.11.001

16. Billings J, Anderson GM, Newman LS. Recent findings on preventable hospitalizations. Health Aff. (1996) 15:239-49. doi: 10.1377/hlthaff.15.3.239

17. Niefeld MR, Braunstein JB, Wu AW, Saudek CD, Weller WE, Anderson GF. Preventable hospitalization among elderly medicare beneficiaries with type 2 diabetes. Diabetes Care. (2003) 26:1344-9. doi: 10.2337/diacare.26.5.1344

18. Khullar D, Zhang Y, Kaushal R. Potentially preventable spending among highcost medicare patients: implications for healthcare delivery. J Gen Intern Med. (2020) 35:2845-52. doi: 10.1007/s11606-020-05691-8

19. Figueroa JF, Joynt Maddox KE, Beaulieu N, Wild RC, Jha AK. Concentration of potentially preventable spending among high-cost medicare subpopulations: an observational study. Ann Intern Med. (2017) 167:706-13. doi: 10.7326/M17-0767

20. Graven PF, Meath THA, Mendelson A, Chan BKS, Dorr DA, McConnell KJ. Preventable acute care spending for high-cost patients across payer types. $J$ Health Care Finance. (2016) 42:1-22.

21. Lu S, Zhang L, Klazinga N, Kringos D. More public health service providers are experiencing job burnout than clinical care providers in primary care facilities in China. Hum Resour Health. (2020) 18:95. doi: 10.1186/s12960-020-00538-Z

22. Zhang Y, Chen Y, Zhang X, Zhang L. Current level and determinants of inappropriate admissions to township hospitals under the new rural cooperative medical system in China: a cross-sectional study. BMC Health Serv Res. (2014) 14:649. doi: 10.1186/s12913-014-0649-3

23. Chen T, Pan J. The effect of spatial access to primary care on potentially avoidable hospitalizations of the elderly: evidence from Chishui City, China. Soc Indic Res. (2020). doi: 10.1007/s11205-020-02413-9

24. Falster MO, Jorm LR, Douglas KA, Blyth FM, Elliott RF, Leyland AH. Sociodemographic and health characteristics, rather than primary care supply, are major drivers of geographic variation in preventable hospitalizations in Australia. Med Care. (2015) 53:436-45. doi: 10.1097/MLR.0000000000000342

25. Freund T, Campbell SM, Geissler S, Kunz CU, Mahler C, Peters-Klimm F, et al. Strategies for reducing potentially avoidable hospitalizations for ambulatory care-sensitive conditions. Ann Fam Med. (2013) 11:363-70. doi: 10.1370/afm.1498

26. Longman JM, Rix E, Johnston JJ, Passey ME. Ambulatory care sensitive chronic conditions: what can we learn from patients about the role of primary health care in preventing admissions? Aust J Prim Health. (2018) 24:304. doi: 10.1071/PY17191

27. van Loenen T, van den Berg MJ, Westert GP, Faber MJ. Organizational aspects of primary care related to avoidable hospitalization: a systematic review. Fam Pract. (2014) 31:502-16. doi: 10.1093/fampra/cmu053

28. Rosano A, Loha CA, Falvo R, van der Zee J, Ricciardi W, Guasticchi G, et al. The relationship between avoidable hospitalization and accessibility to primary care: a systematic review. Eur J Public Health. (2013) 23:356-60. doi: 10.1093/eurpub/cks053
29. Lu S, Niu Y, Zhang Y. Analysis on the characteristic of annual individual medical expenditure for rural residents. Chin Health Econ. (2017) 36:77-80. doi: 10.7664/CHE20170321

30. Xu J, Zheng J, Li J, Xu L. Measurement and difference analysis of catastrophic health expenditure of urban and rural households under the coverage of National Health. Health Econ Res. (2019) 36:35-8. doi: 10.14055/j.cnki.33-1056/f.2019.03.011

31. Office of National Medical Security Bureau. Notice on Printing and Distributing the Subgroups Scheme (version 1.0) of China Healthcare Security Diagnosis Related Groups (CHS-DRG) from the Office of National Medical Security Bureau. (2020). Available online at: http://www.gov.cn/zhengce/ zhengceku/2020-06/19/content_5520572.htm (accessed August 20, 2021).

32. Agency for Healthcare Research and Quality. Prevention Quality Indicators Overview. Available online at: https://www.qualityindicators.ahrq.gov/ Modules/pqi_resources.aspx (accessed January 5, 2021).

33. Andersen RM, Davidson PL. Improving access to care in america: individual contextual indicators. In: Changing the U.S. Health Care System: Key Issues in Health Services Policy and Management. San Francisco, CA: Jossey-Bass (2007). p. 3-32.

34. Joynt KE, Figueroa JF, Beaulieu N, Wild RC, Orav EJ, Jha AK. Segmenting high-cost medicare patients into potentially actionable cohorts. Healthcare. (2017) 5:62-7. doi: 10.1016/j.hjdsi.2016.11.002

35. Powers BW, Yan J, Zhu J, Linn KA, Jain SH, Kowalski JL, et al. Subgroups of high-cost medicare advantage patients: an observational study. J Gen Intern Med. (2019) 34:218-25. doi: 10.1007/s11606-018-4759-1

36. Li X, Krumholz HM, Yip W, Cheng KK, De Maeseneer J, Meng Q, et al. Quality of primary health care in China: challenges and recommendations. Lancet. (2020) 395:1802-12. doi: 10.1016/S0140-6736(20)30122-7

37. Xu W, Pan Z, Lu S, Zhang L. Regional heterogeneity of application and effect of telemedicine in the primary care centres in rural China. Int J Environ Res Public Health. (2020) 17:4531. doi: 10.3390/ijerph17124531

38. Sun M, Rasooly A, Jian W. Quality of primary health care in China: an analysis of data from a nationwide longitudinal survey. Lancet. (2018) 392:S74. doi: 10.1016/S0140-6736(18)32703-X

39. Fang L, Gao P, Bao H, Tang X, Wang B, Feng Y, et al. Chronic obstructive pulmonary disease in China: a nationwide prevalence study. Lancet Respir Med. (2018) 6:421-30. doi: 10.1016/S2213-2600(18)30103-6

40. Hao G, Wang X, Chen Z, Zhang L, Zhang Y, Wei B, et al. Prevalence of heart failure and left ventricular dysfunction in China: the China Hypertension Survey, 2012-2015. Eur J Heart Fail. (2019) 21:1329-37. doi: 10.1002/ejhf.1629

Conflict of Interest: The authors declare that the research was conducted in the absence of any commercial or financial relationships that could be construed as a potential conflict of interest.

Publisher's Note: All claims expressed in this article are solely those of the authors and do not necessarily represent those of their affiliated organizations, or those of the publisher, the editors and the reviewers. Any product that may be evaluated in this article, or claim that may be made by its manufacturer, is not guaranteed or endorsed by the publisher.

Copyright (c) 2022 Lu, Zhang, Zhang, Klazinga and Kringos. This is an open-access article distributed under the terms of the Creative Commons Attribution License (CC $B Y)$. The use, distribution or reproduction in other forums is permitted, provided the original author(s) and the copyright owner(s) are credited and that the original publication in this journal is cited, in accordance with accepted academic practice. No use, distribution or reproduction is permitted which does not comply with these terms. 